DOSSIÊ TEMÁTICO: Educação, currículo e juventudes: dilemas e desafios atuais

dol https://doi.org/10.22481/praxisedu.v16i42.7336

\title{
A JUVENILIZAÇÃO DA EDUCAÇÃO DE JOVENS E ADULTOS: DESAFIOS E POSSIBILIDADES CURRICULARES
}

\author{
THE JUVINILIZATION OF YOUTH AND ADULT EDUCATION: CHALLENGES AND \\ CURRICULAR POSSIBILITIES
}

\section{LA JUVENILIZACIÓN DE LA EDUCACIÓN DE JÓVENES E ADULTAS DESAFÍOS Y POSIBILIDADES}

\author{
Maria da Conceição Cédro Vilas Bôas de Oliveira \\ Universidade do Estado da Bahia - Brasil \\ Graça dos Santos Costa \\ Universidade do Estado da Bahia - Brasil \\ Universidade de Barcelona - Espanha
}

\begin{abstract}
Resumo: O objetivo do presente texto é apresentar os resultados da pesquisa desenvolvida no Programa de Pós-Graduação em Educação de Jovens e Adultos do Mestrado Profissional - MPEJA da Universidade do Estado da Bahia (UNEB), que teve por objetivo analisar as representações sociais dos(as) estudantes da EJA de uma escola da rede estadual de ensino do Estado da Bahia, acerca de currículo e juventude, ressaltando os desafios e as possibilidades na construção de um currículo que atenda às culturas juvenis. Metodologicamente, utilizou-se a abordagem qualitativa, por meio de estudo de caso. Os resultados revelam muitos desafios e possibilidades a serem trilhados. Sinalizam a necessidade da escola revisitar suas arquiteturas e práticas curriculares, para maior aproximação das juventudes; conhecer as diferentes culturas juvenis dos estudantes, ou seja, conhecer os sujeitos da ação educativa, garimpando elementos para esculpir as particularidades e reconfigurações curriculares da EJA; fomentar ações formativas colaborativas, pautadas em giro curricular de insurgências e inclusão.
\end{abstract}

Palavras chave: Currículo. Educação de jovens e adultos. Juventudes.

Abstract: The objective of this article is to present the results of the research carried out in the Professional Master's Program in Youth and Adult Education - MPEJA - of the Bahia State University (UNEB), whose objective was to analyze the social representations of students from EJA at a state school in the state of Bahia, on the curriculum and youth, highlighting the challenges and possibilities in the construction of a curriculum that addresses youth cultures. Methodologically, the qualitative approach was used, through a case study. The results reveal many challenges and possibilities to follow. They point out the need of the school to look for its architecture and curricular practices, to 
approach young people; to know the different youth cultures of the students, that is to say, to know the themes of the educational action, to look for elements to sculpt the particularities and curricular reconfigurations of EJA; Promote collaborative training actions, based on the curriculum of insurgencies and inclusion.

Key words: Youth and adult education. Curriculum. Youths.

Resumen: El objetivo de este artículo es presentar los resultados de la investigación desarrollada en el Programa de Máster Profesional de Educación de Jóvenes y Adultos - MPEJA - de la Universidad del Estado de Bahía (UNEB), cuyo objetivo fue analizar las representaciones sociales de estudiantes de EJA en una escuela estatal en el estado de Bahía, sobre el currículum y la juventud, destacando los desafíos y las posibilidades en la construcción de un currículo que atienda las culturas juveniles. Metodológicamente, se utilizó el enfoque cualitativo, a través de un estudio de caso. Los resultados revelan muchos desafíos y posibilidades a seguir. Señalan la necesidad de la escuela de buscar su arquitectura y prácticas curriculares, para acercarse a los jóvenes; conocer las diferentes culturas juveniles de los alumnos, es decir, conocer los temas de la acción educativa, buscar elementos para esculpir las particularidades y reconfiguraciones curriculares de EJA; Fomentar acciones de formación colaborativa, basadas en el currículum de insurgencias e inclusión.

Palabras clave: Educación de jóvenes y adultos. Currículo. Juventudes.

\section{Introdução}

A Declaração dos Direitos Humanos, datada de 1948, enceta que todos os seres humanos possuem direitos com igualdade e equidade, independente de quem eles sejam, quais posições eles ocupem em seus contextos de vida, seja no aspecto econômico, político, social ou cultural, sem distinção e discriminação de qualquer espécie de etnia, religião, gênero, nacionalidade ou qualquer outra condição originária de vida. $\mathrm{O}$ direito à educação, como um direito humano para todos e todas, não foge a essa garantia e a essa regra.

No trato da garantia dos direitos à educação para jovens e adultos, os horizontes legislativos no Brasil, em consonância com a Declaração Universal dos Direitos Humanos DUDH, legitimam a Educação de Jovens e Adultos-EJA pela Constituição Federal de 1988 e pela Lei de Diretrizes e Bases da Educação Nacional - 9394/96 - LDB. Nesta premissa, a LDB estabelece, no seu art.37, no parágrafo $1^{\circ}$, que "Os sistemas de ensino assegurarão gratuitamente aos jovens e aos adultos, [...] oportunidades educacionais apropriadas, consideradas as características do alunado, seus interesses, condições de vida e de trabalho [...]” (BRASIL, 1996, n.p.). No parágrafo supracitado, as palavras oportunidades, interesses e condições de vida dos estudantes descortinam pluralidades, heterogeneidades presentes no cotidiano escolar, imbricadas por diferentes etnias, religiões, vestuários, locais de moradias, 
gênero, dentre outros e, portanto, nos remetem à importância da discussão sobre a Juvenilização e Currículo Escolar no âmbito da modalidade da Educação de Jovens e Adultos.

Nesse contexto, as heterogeneidades que adentram as escolas e se fazem presentes nas classes revelam a todo instante que as discussões sobre as questões e a complexidade da EJA não se findam na esfera da legislação ou no interior das especificidades da Educação de Jovens e Adultos (ARROYO, 2011), refletindo programas, projetos, recursos didáticos, currículos, organizações e políticas públicas nem sempre bem estabelecidas, pois a EJA é "Um campo aberto a todo cultivo e onde vários agentes participam. De semeaduras e cultivos nem sempre bem definidos ao longo de sua tensa história” (ARROYO, 2011, p. 19).

O tratamento e as incursões na Educação de Jovens e Adultos não podem estar desvinculados em perceber esta modalidade como um "[...] campo carregado de complexidades que carece de definições e posicionamentos claros" (ARROYO, 2011, p.7), além de abarcar "processos formativos diversos, em que podem ser incluídas iniciativas visando [...] à formação política e a questões culturais" (DI PIERRO, 2001, p. 58).

Vejamos que a partir de leituras Paiva (1987), é possível inferir que a EJA no Brasil, desde os seus primórdios, sempre foi sinônimo de complexidade, por provir de enredamentos com os cenários políticos, econômicos, sociais e culturais, a julgar pelo trabalho dos jesuítas em construir modelos de comportamentos europeus na população indígena do Brasil, que "se tratava da aculturação sistemática dos nativos através da educação" (PAIVA, 1987, p. 56).

$\mathrm{Na}$ atualidade, constata-se essa complexidade também por um processo de juvenilização da EJA, que reclama por esforços da escola em visibilizar a grande quantidade de jovens presentes nas classes. Para além, a escola deve promover aproximações e reconhecimento das pluralidades e heterogeneidades das diferentes juventude(s), constituídas historicamente, socialmente e culturalmente, ecoadas pelos estudantes dessa modalidade de ensino, o que favorece novas configurações e reestruturações curriculares e diferentes emersões metodológicas. Esses sujeitos históricos concretos apontam na atualidade mais uma especificidade para a Educação de Jovens e Adultos e, ao mesmo tempo em que apontam, tensionam os espaços e cotidianos escolares, tensionam os currículos, os planejamentos, com sua forma própria de ser, de ver e sentir a vida (ARROYO, 2011).

Neste contexto de tensão e desafios, a faixa etária da EJA vem se tornado cada vez mais ampliada, demandando respostas formativas e curriculares. Nas últimas décadas, tem-se observado uma progressiva presença de estudantes jovens na EJA, fenômeno ao qual Silva (2014, p.35) denomina de "juvenilização". Este fato sinaliza para todos os envolvidos com 
esta modalidade de ensino a premência de reestruturações curriculares, de novas incisões metodológicas, a necessidade de incorporar essa discussão aos momentos formativos dos professores, objetivando alargar seus conhecimentos sobre as juventudes, tendo em vista os desafios advindos desta nova configuração.

A presença dos jovens na EJA vem provocando grandes desafios formativos e curriculares. Segundo Pais (2003, p.35), é “necessário penetrar nos meandros do quotidiano dos jovens" e desvelar suas diferentes formas de vida, como pensam seus estilos e comportamentos, que estão presentes nos mais variados cotidianos de vida, o que nos possibilita visibilizar as diferentes juventudes.

O objetivo deste artigo é apresentar alguns resultados da pesquisa ${ }^{1}$ das representações sociais dos estudantes da EJA acerca de currículo e juventude, ressaltando os desafios e possibilidades para a construção de um currículo que atenda à cultura juvenil. Inicialmente, neste artigo, refletiremos sobre as questões que perpassam sobre a Juvenilização da Educação de Jovens e Adultos. No segundo, faremos uma breve revisão sobre currículo e representações. A seguir, apresentaremos um estudo de caso sobre as representações dos jovens da EJA sobre currículo e juventudes. Por fim, os resultados da pesquisa, revelando os desafios e possibilidades para a construção de um currículo que atenda à cultura juvenil.

\section{Juvenilização nas classes da educação de jovens e adultos}

No Brasil, nas últimas décadas, as escolas que ofertam a modalidade da EJA estão apresentando um gradativo aumento da presença de jovens ${ }^{2}$ estudantes em suas classes, o que vem sendo conhecido e denominado por pesquisadores (BRUNEL, 2014) como o fenômeno da Juvenilização da EJA. Este fenômeno é impulsionado por uma complexidade de fatores de diversas ordens, como, por exemplo, aspectos: legais, pedagógicos, sociais, econômicos e subjetivos.

Os processos migratórios dos jovens da escola regular para a modalidade EJA, segundo Brunel (2014), não estão somente relacionados à existência de um contexto

\footnotetext{
${ }^{1}$ Currículo e Culturas Juvenis: um estudo de caso sobre as representações sociais dos estudantes da Educação de Jovens e Adultos no município de Conceição da Feira-BA. 2016. 245 f. Dissertação (Mestrado) - Programa de Pós-Graduação Profissional em Educação de Jovens e Adultos, Universidade do Estado da Bahia, Salvador, 2016.

${ }^{2}$ Como nos afirma (CONCEIÇÃO, 2015, p. 2.), embora a diversidade etária da EJA não seja um fenômeno absolutamente novo, o que parece ser recente é a discussão acerca da inclusão, salientando as especificidades de cada grupo geracional, suas distintas concepções e anseios, vivências e perspectivas culturalmente contextualizadas.
} 
normativo demarcado pela Lei de Diretrizes e Bases da Educação Nacional de 1996 (BRASIL, 1996), que favoreceu o ingresso antecipado nessa modalidade, estabelecendo a idade de 15 anos como mínima para que os jovens prestem os exames para a conclusão do ensino fundamental, mas também um contexto social e pedagógico mais amplo, no qual se inserem os jovens e as escolas.

A juvenilização da EJA está relacionada à necessidade imediata de trabalho para provimento de uma renda mensal, essencial no sustento da família, uma vez que, "empurrados pelas estratégias de sobrevivência pessoal/ ou familiar, os jovens se sentiriam instados ou se veriam compelidos a "precocemente" exercitar a procura por ocupação" (BRANCO, 2011, p. 131).

Um outro fator potencializador da juvenilização é a possibilidade da conclusão dos estudos em um período curto de tempo, como forma de recuperar o tempo perdido decorrente das sucessivas reprovações e evasões escolares, "consequências das gravíssimas deficiências do sistema escolar e que explicam a defasagem existente entre idade e série; a dificuldade de acesso; a ausência de motivação para permanecer na escola; a busca por certificação" (PEREIRA; OLIVEIRA, 2018, p. 531).

Os fatores pedagógicos dizem respeito à dissonância entre a organização e a estruturação do ensino do diurno à dinâmica da vida dos jovens. Os horários das aulas, que muitas vezes são incompatíveis com a vida do estudante trabalhador, as tarefas e os trabalhos escolares também representam um fator pedagógico que alarga o descompasso entre o ensino do diurno e os objetivos de vida dos estudantes, dado que as tarefas e trabalhos escolares do diurno são muitas vezes consolidados através de dinâmicas de trabalhos em grupos, frequentemente realizadas no turno oposto, geralmente na escola e/ou na casa dos colegas, dinâmicas estas que acabam por se constituírem em impedimentos dentro do cotidiano desses estudantes.

Os entraves do sistema de ensino regular, por meio de seus arranjos didáticos e curriculares inflexíveis e herméticos, é um fato que produz trajetórias com interrupções no ensino diurno, devido a recorrentes reprovações, o que acaba deixando os estudantes desconfortáveis e apartados do ensino neste turno. E, por fim, há o desejo de concluírem uma etapa do seu processo de escolarização, que foi abandonado anteriormente, certamente pelo próprio percurso excludente de vida, retratado por muitas lacunas, mas não "apenas das lacunas escolares truncadas, mas vêm das múltiplas lacunas a que a sociedade os condena" (ARROYO, 2011, p.24). 
A partir deste complexo cenário, o fenômeno da juvenilização reclama por estudos e investigações no campo da Educação de Jovens e Adultos, interconectados com estudos sobre as juventudes e as culturas juvenis, ou seja, os estudos sobre as juventudes ancoram as discussões sobre a EJA. Nosso interesse neste artigo é discutir as representações sociais dos jovens sobre o currículo e juventudes e apresentar os desafios e possibilidades para o currículo, que atenda às culturas juvenis.

Pensar as juventudes nas escolas significa um campo amplo de discussão e debates. Como contribuição, destacamos, como precursora, fruto das pesquisas e levantamentos coordenados pela Dra Marília Pontes Sposito, a publicação O Estado da Arte sobre juventude na pós-graduação brasileira: Educação, Ciências Sociais e Serviço Social (1999-2006). Esta relevante pesquisa demonstra que a abordagem do tema juventude e escola concentra-se em amplitude no campo da Educação, o que é justificado pelo rejuvenescimento dos estudantes presentes no Ensino Médio, pelos cenários atuais que circundam as juventudes nas esferas econômicas, sociais e culturais, dentre outras questões. Como subtemas para o tema Juventude e Escola, a pesquisa ressalta: Indisciplina e Violência na escola e Juventude; Significados atribuídos à escola e seus processos; Programas e propostas educativas sob a ótica dos alunos; Identidades/subjetividades juvenis e escolas; Culturas juvenis e Escolas, dentre outros.

Esse conjunto de estudos substanciam as discussões sobre as juventudes, as culturas juvenis e, por conseguinte, são imprescindíveis para entender algumas das complexidades da EJA na atualidade. De acordo com a reflexão de Silva (2014), a "juvenilização" vem tensionando mudanças significativas nessa modalidade de ensino “[...] Com isso, surgem novos desafios para educadores da EJA [...] que veem o ambiente escolar se modificando com novas formas de linguagem, aprendizagem, cultura e convívio" (SILVA, 2014, p.35). Estes caminhos que devem ser percorridos e esquadrinhados pela escola no âmbito do currículo, do planejamento e das metodologias, necessitam intencionar e oportunizar um movimento dialógico com equidade e horizontalidades envolvendo a comunidade escolar, reconfigurando de forma mais incisiva e intensa o trabalho e os espaços da escola como um todo.

Pensar em juventudes é atrelar a estas distintas formas de linguagens, de vestir, do uso de adereços, comportamentos e convivências no mundo, que indicam diferentes pertencimentos e identidades, pois as juventudes são historicamente, socialmente, culturalmente e economicamente construídas (GROPPO, 2000). 
A partir deste prisma, invalidamos o conceito de juventudes de forma unívoca, homogênea, hermeticamente fechada, invocando a classificação por faixa etária para definição de uma categoria social (GROPPO, 2000), pois “quando falamos de jovens das classes médias ou de jovens operários, de jovens rurais ou urbanos, de jovens estudantes ou trabalhadores, de jovens solteiros ou casados, estamos a falar de juventudes em sentido completamente diferente da juventude quando referida a uma fase de vida" (PAIS, 2003, p. 42), ou classificando as juventudes como uma etapa transitória da vida ou uma etapa preparatória para a vida adulta, dado que o "jovem e seu comportamento mudam de acordo com a classe social, o grupo étnico, a nacionalidade, o gênero, o contexto histórico, nacional e regional" (GROPPO, 2000, p.9-10). Em acréscimos sobre a compreensão da juventude no viés sociológico, Pais (2003, p. 37) apresenta que “A juventude é uma categoria socialmente construída, formulada no contexto de particulares circunstâncias econômicas, sociais ou políticas; uma categoria sujeita, pois, a modificar-se ao longo do tempo".

Alicerçada pelo viés sociocultural (GROPPO, 2000), Pais (2003), a compreensão das juventudes por um simples enquadramento de faixa etária é insuficiente e limitador para entender a diversidade impressa em cada jovem em sala de aula, uma vez que a juventude "é vivida com muita diversidade na realidade cotidiana, devido a sua combinação com outras situações sociais [...], e também às diferenças culturais, nacionais e de localidade, bem como às distinções de etnia e de gênero" (GROPPO, 2000, p. 15).

Posteriores às pesquisas de Sposito (2009) sobre a juventude supracitada, outras investigações acenam para a importância do reconhecimento e da interpretação dessa diversidade na realidade cotidiana dos jovens na EJA, acrescentando também para o entendimento das relações complexas vivenciadas pela Educação de Jovens e Adultos na atualidade, a exemplo da pesquisa de Chaves Vale (2007), visando compreender as experiências dos jovens estudantes da EJA, e se essas demandas juvenis advindas dessas experiências estão sendo acolhidas e atendidas pela escola.

Também a investigação realizada por Moreno (2010) tem com princípio que a compreensão dos modos de vida do jovem da Educação de Jovens e Adultos é fundamental para o desenvolvimento das práticas educativas destes jovens. Ainda incluímos, nesta discussão, a pesquisa organizada por Maia (2010), que busca mapear e analisar as experiências e representações a respeito do que é ser jovem e sobre a juventude na Educação de Jovens e Adultos, e a pesquisa desenvolvida por Pinho (2016), que busca investigar o que 
está sendo exequível em termos de educação e cultura popular em distintas propostas escolares da EJA.

O cenário acima configurado, em relação às juventudes nas classes da EJA, revelam a complexidade e os desafios que o processo de juvenilização imprime à Educação de Jovens e Adultos, no sentido também do reconhecimento das diferentes juventudes presentes em sala de aula, pois os jovens estão encharcados com suas identidades, visibilizando-as no espaço escolar de diversas formas, pela música, por comportamentos, linguagens, dentre outras, dado que as juventudes vêm "se revelando como um tempo humano, social, cultural, identitário que se faz presente nos diversos espaços da sociedade" [...] (ARROYO, 2011, p. 21).

\section{Currículo e representações: diálogos necessários}

O desvelamento e a visibilização das diferentes juventudes no currículo da EJA implicam em fazer um giro curricular didático e epistemológico. O currículo é um território tensionado, em que todos os sujeitos requerem/exigem respeito, valorização e reconhecimento. "É um espaço de (com) vivências, em que todas as vozes, desejos, representações devem ser acolhidos" (MALLOWS; DOS SANTOS COSTA; COSTA, 2020, p.2).

O currículo, como "um artefato social e cultural" (MOREIRA e TADEU, 2011, p. 13), é fundamental para ecoar os interesses e as diferentes culturas juvenis nos cenários curriculares da EJA, o que demanda confrontos com currículos rígidos, predeterminados, homogêneos, pasteurizados, hierarquizantes e excludentes, facultando, no lugar deste, um cenário curricular plural e inclusivo, que atenda a diferentes culturas juvenis, visto que "a educação é capaz de oferecer, tanto aos jovens como aos adultos, a possibilidade de questionar e desconstruir os mitos de superioridade e inferioridade entre grupos humanos, que foram introjetados neles pela cultura racista na qual foram socializados" (MUNANGA, 2005, p. 17).

Neste entendimento, um currículo socialmente e culturalmente construído pelos diferentes atores do processo educativo demanda escutas, cuidado, escolhas, práticas pedagógicas e posicionamentos políticos relativos ao cotidiano escolar da EJA e da cultura juvenil, pois "enquanto não levarmos a sério a intensidade do envolvimento da educação com o mundo real das alternantes e desiguais relações de poder, estaremos vivendo em um mundo divorciado da realidade" (APPLE, 2008, p. 51). 
Para romper com esse divórcio da realidade, os professores são sujeitos centrais nas disputas curriculares. "Suas implicações com o projeto educativo, suas interpretações sobre os conhecimentos, suas formas de planejar as atividades, suas tomadas de decisões e suas interlocuções com os estudantes/ a comunidade influenciam diretamente no projeto educativo" (MALLOWS; DOS SANTOS COSTA; COSTA, 2020, p.2). Neste contexto de reconfigurações curriculares da EJA, é importante considerar os desafios e implicações do trabalho realizado pelo professor em sala de aula, levando-se em consideração suas escolhas e práticas pedagógicas. Tal contexto aponta para a importância de um investimento na formação continuada do professor da EJA quanto ao trato com o currículo e as juventudes, cuja importância é sedimentada também pela compreensão de que "na atividade pedagógica relacionada com o currículo, o professor é um elemento de primeira ordem na concretização desse processo" (SACRISTÁN, 2000, p.165).

Nesta esfera, há premência dos professores da EJA em reconfigurar seus cotidianos escolares, em redesenhar a arquitetura do currículo e de "outras" práticas curriculares, pois, à medida que os estudantes ultrapassam os muros da escola, perfilam outros cenários do terreno escolar, com outras experiências e contextos de vida, mostrando-se "[...] Outros Sujeitos, nas relações políticas, econômicas, culturais; Outras Pedagogias são inventadas, outras formas de pensá-los e de pensar a educação; o conhecimento, a docência são reinventados"(ARROYO, 2014, p. 11).

Neste sentido, a escola deve criar espaços de trocas de relações dialógicas igualitárias, horizontalmente constituídas, intencionando promover um currículo que favoreça o reconhecimento das diferentes culturas juvenis na EJA. Forjar relações dialógicas e igualitárias, no âmbito do currículo da EJA, é abrir caminhos para o desvelamento e aproximações de outras arquiteturas subjetivas e plurais de vida dos jovens estudantes, sendo necessário, para tal fim, gerenciar conflitos, disputas e embates, visto que "as relações culturais não são idílicas, não são relações românticas, [...], estão atravessadas por questões de poder, por relações fortemente hierarquizadas, marcadas pelo preconceito e discriminação de determinados grupos" (MOREIRA; CANDAU, 2013, p. 23).

Neste contexto, ao despir e visibilizar as diferentes arquiteturas de vida dos estudantes da EJA, a escola exercita receptividade, flexibilidade, sensibilidade e sutilezas no olhar ante a apreensão e o reconhecimento das realidades que se instalam dinamicamente na conjuntura escolar. Essa dinamicidade plural é rabiscada pelos jovens, mediante suas inclinações por danças, músicas, por componentes e adereços do vestuário, a exemplo do 
boné, dentre outros elementos. Estes rabiscos são reveladores de crenças, valores, ideias, interações humanas, que se forjam em diferentes contextos e práticas de vida, com implicações no currículo escolar.

Ainda na agenda de discussões, acentuamos Pedra (1997), no trato de uma compreensão crítica do currículo escolar e de seus imbricamentos com as juventudes, uma vez que o currículo, enraizado socialmente e culturalmente, está para além da seleção de conteúdos dados, que, ao "selecionar, classificar, distribuir e avaliar conhecimentos põe em ação as múltiplas representações que percorrem os espaços culturais, não somente aquelas elaboradas pelos grupos dominantes" (PEDRA, 1997, p. 60). Nesta conjuntura, compreendemos que o currículo da escola lócus da investigação é encharcado de representações sociais, reveladas em posicionamentos frente a uma situação de vida, nas falas, discursos e mensagens dos estudantes ao tratar de currículo e juventudes.

As experiências dos jovens, as práticas culturais forjadas em diferentes contextos de vida, as relações estabelecidas com o "outro", amplificadas pela comunicação, mesmo que inconscientemente, entrelaçam, constroem, reconstroem as representações sociais que permeiam suas vidas. Ao posicionar-se e dialogar sobre uma música, uma dança, o uso do boné e demais aspectos de vida, os jovens acionam, revelam, modificam e reconfiguram suas representações sociais, dinâmica que estabelece o espaço escolar e o campo do currículo, essenciais na aproximação, no reconhecimento, nas construções e reconstruções de representações sociais, tendo em vista as juventudes.

Com o intuito de nos aproximarmos de forma mais densa das subjetividades e significados emanados dos estudantes sobre currículo e juventudes, nos amparamos na teoria das Representações Sociais - RS para analisarmos os desafios e possibilidades na construção de um currículo que atenda à cultura juvenil. Assim, partimos da ideia de:

Um sistema de valores, ideias e práticas, com uma dupla função: primeiro, estabelecer uma ordem que possibilitará às pessoas orientar-se em seu mundo material e social e controlá-lo; e, em segundo lugar, possibilitar que a comunicação seja possível entre os membros de uma comunidade, fornecendo-lhes um código para nomear e classificar, sem ambiguidades, os vários aspectos de seu mundo e da sua história individual e social. (MOSCOVICI, 2012, p.21).

O referido teórico ainda aponta que as representações sociais são "todas as interações humanas, surjam elas entre duas pessoas ou entre dois grupos, e pressupõem representações" (MOSCOVICI, 2012, p. 40). Também, Guareschi e Jovchelovitch (1995) contribuem na 
discussão das Representações Sociais e no entendimento da construção dos diferentes saberes sociais, uma vez que é através das RS que os sujeitos, envolvendo afeto, emoções e conflitos de pontos de vista, engendram diferentes culturas juvenis, constroem posicionamentos, formas de olhar, perceber e lidar com o mundo que os rodeia, tecendo e destecendo a realidade que se apresenta a sua frente. Segundo esses mesmos "O caráter simbólico e imaginativo desses saberes traz à tona a dimensão dos afetos, porque, como sujeitos sociais, eles se empenham em entender e dar sentido ao mundo, eles também o fazem com emoção, com sentimento e com paixão" (GUARESCHI; JOVCHELOVITCH, 1995, p.20).

Em continuidade, Jodelet (2001, p. 28) sublinha a comunicação social "como condição de possibilidades e de determinação das representações e do pensamento social". Essa comunicação possibilita o compartilhamento das diferentes representações sociais com os indivíduos em diferentes contextos de vida, pois " [...] compartilhamos o mundo com outros, neles nos apoiamos, às vezes convergindo; outras divergindo para compreendê-lo, gerenciá-lo ou afrontá-lo. Por isso, as representações sociais são tão importantes na vida cotidiana" (JODELET 2001, p. 17).

As representações sociais se constituem como um componente basilar para a interpretação dos imaginários, dos significados, das interpretações e análises dos fatos, elementos e atitudes, dos posicionamentos dos estudantes, que, direta ou indiretamente, acabam trazendo implicações para a educação, para todo o cotidiano escolar e, consequentemente, para o currículo e para a prática dos professores em sala de aula.

Desse modo, pode-se afirmar que o currículo escolar é um espaço de representações sociais, por este ser um artefato histórico, social e culturalmente construído (MOREIRA e TADEU, 2011), o que demanda escolhas e seleção de conhecimentos e práticas que refletem as representações sociais dos sujeitos envolvidos nos processos de ensino e aprendizagens da escola.

\section{Um estudo de caso sobre as representações acerca do currículo e juventudes}

Metodologicamente, nos amparamos nos horizontes da abordagem qualitativa, buscando "trabalhar com o universo dos significados, dos motivos, das aspirações, das crenças, dos valores e das atitudes" (MINAYO, 2013, p. 21). Pretendemos, por meio do Estudo de Caso, tendo em vista, "[...] "interpretação em contexto"; [...] retratar a realidade de forma completa e profunda; $[. .$.$] representar os diferentes e às vezes conflitantes pontos de$ 
vista presentes numa situação social” (LUDKE; ANDRÉ, 1986, p. 18-20). Em contribuição, Gil (2009, p. 55) declara que "os estudos de caso requerem profundidade, preservação do caráter unitário do caso e a não separação de seu contexto", características estas reclamadas por esta investigação. Em consonância com o método de investigação, foi realizada uma pesquisa exploratória inicialmente, no lócus de investigação, constituindo uma importante fonte de observação, estruturação e possíveis reconfigurações da pesquisa. Para esse fim, foram realizadas 07 visitas ao lócus de investigação, agendadas previamente com o intuito de: apresentar o projeto de pesquisa à gestão da unidade escolar; visitar a sala de aula da EJA para apresentar aos estudantes o projeto de pesquisa; visitar a secretaria da escola para coleta de informações sobre os estudantes da EJA; coletar assinaturas dos documentos de autorização da pesquisa; e realizar aplicação, em fase de teste, do questionário socioeconômico.

Com o intuito de comprovar o aumento da presença de estudantes jovens nas classes da EJA, na escola lócus da investigação, foram analisados os dados de matrícula dos estudantes dessa modalidade, referentes aos anos de 2014 e 2015, buscando uma relação entre a quantidade de estudantes e as décadas de nascimento dos matriculados na EJA no turno noturno. Esse levantamento e a análise destes dados foi um dos elementos que ajudaram a comprovar o que, a olhares mais atentos, já visualizávamos nas classes da EJA: o fenômeno da Juvenilização. Abaixo, apresentamos estes dados, com algumas considerações (ver tabela a seguir).

Tabela $03^{3}$ - Relação entre quantidade de estudantes matriculados na EJA por décadas

\begin{tabular}{|c|c|c|}
\hline Década de nascimento & $\begin{array}{c}\text { Quantidade de Estudantes } \\
\text { em 2014 }\end{array}$ & $\begin{array}{c}\text { Quantidade de Estudantes } \\
\text { em 2015 }\end{array}$ \\
\hline Década de 1950 & 02 & 01 \\
\hline Década de 1960 & 08 & 06 \\
\hline Década de 1970 & 19 & 17 \\
\hline Década de 1980 & 41 & 35 \\
\hline Década de 1990 & 100 & 129 \\
\hline Total & 170 & 188 \\
\hline
\end{tabular}

Fonte - Elaboração própria, tendo como referência a pesquisa exploratória.

\footnotetext{
${ }^{3}$ Dados retirados da pasta individual dos alunos matriculados na EJA de uma escola da Rede Estadual de Ensino/Bahia em 2014 e 2015. Essa tabela compõe o texto intitulado Políticas públicas: um olhar no processo de juvenilização da educação de jovens e adultos na Bahia, que tem como autoras Ana Célia Dantas Tanure e Maria da Conceição Cédro Vilas Bôas de Oliveira, na ocasião do IX Colóquio Internacional "Educação e Contemporaneidade", em 2015 e também faz parte da dissertação intitulada Currículo e Culturas Juvenis: Um Estudo de caso Sobre as Representações Sociais dos Estudantes da Educação de Jovens e Adultos no Município de Conceição da Feira.
} 
A análise dos dados, expressos na tabela acima, nos permite fazer algumas considerações sobre o crescimento de estudantes matriculados no ano de 2015 em relação a 2014.

As técnicas utilizadas para coleta das informações foram: o questionário Socioeconômico, a Análise Documental e o Grupo Focal ${ }^{4}$, como percursos para analisar as representações sociais dos estudantes acerca de currículo e juventude, ressaltando os desafios e possibilidades para a construção de um currículo que atenda à cultura juvenil.

Em continuidade, o Grupo Focal foi eleito também como mais uma técnica de abordagem para compor a investigação, por possibilitar aos jovens estudantes da EJA condições para que "se situem, explicitem pontos de vista, analisem, infiram, façam críticas, abram perspectivas diante da problemática para a qual foram convidados a conversar coletivamente" (GATTI, 2005, p. 8). A realização do Grupo Focal demandou um planejamento minucioso, no sentido de favorecer aos estudantes um espaço aberto, sem discriminação e exclusões, possibilitando que os mesmos expressem, sem restrições e medos, suas ideias, valores, sentimentos, posicionamentos; ou seja, anunciem suas representações sociais a respeito de currículo e juventude, ressaltando os desafios e possibilidades para a construção de um currículo que atenda à cultura juvenil. Como recurso para a realização dos encontros, escolhemos um painel de imagens de jovens, representado a pluralidade existente em seus contextos de vida. Nosso objetivo no trabalho com as imagens era que os estudantes pudessem, a princípio, se identificar com as mesmas e compreender a inexistência de preconceitos e hierarquizações culturais naquele espaço de discussão. Ainda neste momento, é importante frisar uma preparação e organização do investigador, nos encaminhamentos e na realização dos encontros, no sentido de saber olhar para cada estudante individualmente, saber ouvir e dar encaminhamentos aos registros e a toda dinâmica que envolve a realização do Grupo Focal. Os encontros, no total de 04, seguiram a seguinte organização:

- Encontro 01 (Juventude) - Objetivo: Analisar as representações sociais dos estudantes sobre juventude. Perguntas desencadeadoras: Ao falar de juventude, o que lhe vem à cabeça? O que é juventude para você?

- Encontro 02 (Cultura) - Objetivo: Refletir sobre as diferentes culturas juvenis presentes no cotidiano dos estudantes. Perguntas desencadeadoras: O que você

\footnotetext{
${ }^{4}$ Neste artigo apresentaremos unicamente os resultados do grupo focal e das entrevistas realizadas com os estudantes
} 
pensa ao falar de cultura? Com que outro grupo você se identifica, além da sua família? Quais práticas culturais fazem parte do seu contexto de vida?

- Encontro 03 (Currículo) - Objetivo - Analisar as representações sociais dos estudantes sobre currículo. Pergunta desencadeadora: Ao falar de currículo escolar, o que lhe vem à cabeça?

- Encontro 04 (Currículo) - Objetivo: Analisar os desafios e possibilidades revelados pelos estudantes para a construção de um currículo que atenda à cultura juvenil. Pergunta desencadeadora: Quais são os maiores desafios que os jovens encontram no ambiente escolar em relação à sua cultura juvenil? Em relação às atividades propostas aos estudantes, o que você acha do trabalho desenvolvido pela escola? Como você acha que a escola pode trabalhar com sua forma de ver, sentir e estar no mundo? Para aproximar as atividades escolares dos contextos de vida de vocês, que sugestões você daria à escola?

Por fim, as informações que emergiram da investigação foram esquadrinhadas, analisadas e interpretadas com densidade, elegendo a técnica de Análise de Conteúdo, por considerar que essa técnica "se aplica a discursos [...] extremamente diversificados. [...] é uma hermenêutica controlada, baseada na dedução: a inferência” (BARDIN, 1977, p.11).

Este Estudo de Caso foi realizado no município de Conceição da Feira-BA, em uma escola estadual de ensino médio, com os estudantes da EJA, com início em 2015 e conclusão em 2016. A escolha do lócus de investigação se deve ao fato de a escola: ofertar a modalidade da Educação de Jovens e Adultos; constatar o fenômeno da Juvenilização nas classes da EJA; e a escola desejar participar da investigação. O município de Conceição da Feira-BA, com uma população de 22.226 habitantes em 2013, fica localizado na Região Metropolitana de Feira de Santana-BA, fazendo limites com outros municípios. Sua economia é baseada na avicultura, possui um comércio bastante diversificado e dinâmico. A cidade possui escolas públicas de ensino, nos âmbitos das redes municipal e estadual, como também no âmbito da rede particular de ensino. Em relação ao ensino superior, as cidades circunvizinhas oferecem ao município acesso a faculdades e universidades públicas e privadas.

A escola lócus de investigação possui uma equipe de gestão, coordenadora pedagógica e professores com graduação, especialização e mestrado compondo a sua formação. Em análise à ficha cadastral do professor, percebemos que a escola tem um índice de rotatividade baixo no ensino noturno e muitos desses professores residem na cidade, o que 
possivelmente favorece o conhecimento da comunidade escolar. Quanto à estrutura da escola, a mesma possui uma boa infraestrutura, oportunizando os estudantes a participarem de atividades que estão para além da sala de aula. Estas informações foram importantes para compor e perfilar os cenários das singularidades da escola lócus de investigação, porém verticalizamos de forma mais aprofundada alguns aspectos, importantes para compor a pesquisa, das trajetórias de vida dos estudantes que participaram desta investigação. Neste sentido, buscou-se realizar incursões mais aprofundadas sobre os sujeitos da pesquisa acerca das realidades socioeconômicas e práticas culturais vivenciadas em seus cotidianos.

Os atores da pesquisa foram 11 estudantes do ensino médio de uma escola de educação de jovens e adultos da Rede Estadual de Ensino na cidade de Conceição da FeiraBA. Moram na zona urbana e rural, muitos (45\%) desses estudantes já têm famílias constituídas. Todos os estudantes da investigação trabalham durante o dia e estudam à noite, sendo que $45 \%$ dos estudantes sinalizaram que trabalham para ajudar os pais nas despesas da família. Outros $45 \%$ anunciaram que trabalham para buscar uma independência financeira, e os demais sinalizaram que trabalham em busca de novas experiências.

Os estudantes investigados iniciaram sua trajetória escolar no ensino diurno, sendo impulsionados, pelas negações da vida, fundadas em contextos econômicos e sociais, a migrar para o turno noturno, geralmente por questões de necessidade de trabalho durante o dia. Estes estudantes também sinalizam a escola como um espaço apropriado para a construção de amizades, além de outros locais da cidade. Gostam de diferentes estilos musicais: músicas gospel, pagode, hip-hop e funk. Muitos dos estudantes se declaram de etnia preta, frequentam as igrejas evangélicas ou católicas. O questionário assinala também que os estudantes escutam rádio, assistem TV e possuem celulares com acesso às redes sociais.

Nesta conjuntura, as teias tecidas neste cenário já anunciam os espaços heterogêneos e plurais e, consequentemente, diferentes representações sociais em relação a currículo e juventude nas classes da Educação de Jovens e Adultos.

\subsection{Desvelando as representações sociais dos jovens estudantes da EJA}

A análise das representações sociais dos estudantes é um conjunto de interpretações da realidade (MOSCOVICI, 2012). Essas interpretações da realidade foram se desvelando com os sujeitos da pesquisa, ao participarem do Grupo Focal que buscou discutir, de forma aprofundada e densa, as temáticas de Currículo, Juventude e Cultura, para analisar as 
representações sociais dos estudantes acerca de currículo e juventude, ressaltando os desafios e possibilidades para a construção de um currículo que atenda à cultura juvenil. A seguir, apresentaremos as representações sociais de juventude, categorizadas ${ }^{5}$ a partir das entrevistas e grupos focais: juventude como recorte etário, juventude como um valor, juventude como sinônimo de rebeldia e violência, juventude como uma cultura de ostentação.

As representações sociais dos estudantes sobre juventude são compreendidas como um recorte etário. Analisando a narrativa da estudante Yasmim, ${ }^{6}$ esta demarca claramente essa representação social "Porque, tipo assim. [...]. Por conta da minha idade. Entendeu? Eu então me considero jovem. É por conta da minha idade. Eu tenho 19 anos" (Yasmim). A expressão "por conta da minha idade" reverbera um entendimento da juventude como demarcada por uma fase da vida, em que o rigor etário é elemento fundamental, o que não consubstancia os enredamentos e pluralidades inerentes a diferentes contextos de vida dos jovens. A compreensão da juventude pelo recorte etário, no entendimento da premência de novas reconfigurações curriculares reclamadas pelo fenômeno da juvenilização da EJA, é insuficiente no entendimento da complexidade das questões trazidas pela cultura juvenil e na concepção da escola como um "espaço de cruzamento de culturas, fluido e complexo" (MOREIRA; CANDAU, 2013, p. 15), o que provavelmente pode refrear a organização de um currículo conectado à cultura juvenil.

Entretanto, outras representações sociais foram sinalizadas pelos estudantes, que estão para além do recorte etário, a exemplo da Juventude como um valor, concebido como um comportamento incorporado por muitas pessoas em apreender e manter valores concernentes aos estilos de vida jovem (DEBERT, 2010). Estes estilos de vida se revelam nas roupas, no cabelo, na linguagem, o que é confirmado na fala das estudantes abaixo relacionadas: "Eu acho, assim, a pessoa não depende só da idade, depende como se cuida, como se trata, como se veste para se definir se é uma pessoa jovem ou não [...], como uma pessoa se define, não importa idade”. (Camila) “[...] tem várias formas de dizer que eu sou jovem pelo meu pensamento, através das minhas falas, pelas minhas vestes [...] pelas minhas atitudes, sim, é tudo isso" (Valentina). A representação social como um valor vincula a juventude a comportamentos dinâmicos de vitalidade, de conquista e força, sendo características e comportamentos cobiçados e perseguidos como certo ideal social na

\footnotetext{
${ }^{5} \mathrm{O}$ material coletado passou progressivamente a falar, revelando, assim, gradativamente, diferentes níveis de significação, nas quais as tematizações vão nomeando os dados de campo (Castro, 2011, p. 145).

${ }^{6}$ Os nomes dos estudantes que aparecem na pesquisa são fictícios, para resguardar o anonimato, escolhidos aleatoriamente, sem correspondência nenhuma com o nome original.
} 
sociedade (RIBEIRO, 2004). As vestes, a linguagem, o corte de cabelo e o uso de um adereço também são elementos na compreensão da juventude como um valor, haja vista a fala da estudante Camila, "como se veste para se definir se é uma pessoa jovem ou não", o que significa dizer que adultos e idosos, independente da idade que tenham, podem ser vistos como jovens, a depender de conexões e comportamentos com estilos de vida jovens, da sua vitalidade, da sua forma de pensar e compreender a vida. Segundo Debert (2010, s.p), "a juventude perde conexão com um grupo etário específico e passa a significar um valor que deve ser conquistado e mantido em qualquer idade através da adoção de formas de consumo de bens e serviços apropriados", o que é corroborado na fala da estudante Valentina, expressa acima, “[...] tem várias formas de dizer que eu sou jovem pelo meu pensamento, através das minhas falas". Observe que a estudante ressalta com a expressão "várias formas" a multiplicidade de estilos de vida jovem, pois, nos contextos atuais, a vida social cotidiana se transforma de forma radical, transmutando os contornos mais pessoais da nossa existência (GIDDENS, 2002). Neste entendimento, a juventude ultrapassa os rigores etários, ganhando elementos e contornos de heterogeneidade e, portanto, é vista como um valor social, intricada com vários estilos e formas de ser jovem na atualidade (DEBERT, 2010). Nesta conjuntura, interpretar a juventude como um valor nos permite quebrar estereótipos, diluir imagens e alargar compreensões de comportamentos de todos os que almejam sempre a juventude (DEBERT, 2010).

Em acréscimo, outra Representação Social da juventude é compreendida pelos estudantes como sinônimo de rebeldia e violência. Os desdobramentos dos cenários políticos, econômicos e sociais, pertinentes ao nosso país na atualidade, acabam por provocar contextos de hostilidade, violência e vitimização em uma parcela da população jovem do país, sendo estes jovens a camada da sociedade mais vulnerável a situações de morte e violência (WAILSELFI, 2015). Em consequência, presenciamos e vivenciamos diariamente no cotidiano, pelas mídias sociais e demais meios de comunicação, comportamentos violentos envolvendo vitimização dos jovens, que se acentuam de forma exponencial quando fazemos um recorte de etnia, gênero e classe social, o que acaba por comprometer e dificultar o projeto de vida dos mesmos (ABRAMOVAY et ali. 2002). Em decorrência deste cenário exposto acima, as representações sociais da juventude são perfiladas pelas palavras rebeldia e violência. É o que presenciamos na fala da estudante (Sofia): "Falta de compreensão. Acham que é certo, que podem chegar, roubar, traficar, porque podem ser presos, porque podem acabar morrendo com uma bala perdida, não pensam isso". 
Há uma recorrência dos estudantes em colocar, em um mesmo conjunto, as palavras juventude, violência, conflito e criminalidade, planificando estereótipos de jovens violentos e rebeldes. Ademais, as falas dos estudantes revelam, a um olhar mais acurado, que a violência e a rebeldia são analisadas a partir da ausência de compreensão, por parte dos mesmos, sobre os fatores políticos, econômicos e sociais mais amplos e complexos que gestam os contextos de violências que envolvem os jovens na atualidade. Tal fato ocasiona a compreensão de que a violência é corporificada pelos desejos individuais dos jovens, sendo justificada pela "falta de compreensão" do jovem, porque são incompreensíveis ou inconsequentes (Sofia), o que é relatado também pela fala da estudante (Camila), "Porque acham que é jovem, pode ofender, maltratar, entre outras coisas, que só leva a um caminho que lá para frente vai ser cada vez mais pior. [...]os jovens hoje só querem saber de matar, traficar, [...]”. Todavia, entendemos que essa assimilação se deve por uma inconsistência de argumentos gerada por uma carência de um entendimento crítico da atual situação em que vive a sociedade e particularmente os jovens no país, principalmente os de determinados segmentos sociais (FRAGA; LULIANELLI, 2003).

A representação social dos jovens como sinônimo de rebeldia e violência, criando estereótipos de jovens violentos, são respostas a contextos e cotidianos vividos por estes jovens, materializando-se e ganhando força através das mídias sociais, TV e rádio, cujos meios de comunicação são acessados constantemente pelos jovens estudantes. Todavia essa representação social traz implicações no contexto escolar da Educação de Jovens e Adultos, tendo em vista o fenômeno da juvenilização, no sentido de reconstruções curriculares, no sentido de tensionar a desmistificação de estereótipo de que jovens são propulsores de violência, desconstruir a imagem do jovem ligada à violência, possibilitando aos mesmos, uma apreensão crítica dos diferentes contextos da sociedade, alterando sua forma de encarar e reconhecer a realidade dentro e fora do espaço escolar.

Por fim, as representações sociais da juventude como uma Cultura da Ostentação se traduzem pela forma como roupas, adereços e bens materiais arquitetam enredos na vida dos jovens. Estão ligadas a uma cultura de consumo, de exibicionismo, de ostentação de roupas, celulares, formas de vida, carros, joias, sapatos, bonés, relógios, dentre outras coisas que formam um conjunto de elementos que identificam grupos de jovens que ostentam na vida: “Juventude é a forma de se vestir e um jeito diferente de um jeito e de outro, sapatos novos, roupas novas, celulares, lançamentos. É estar na moda sempre” (Fernando). A fala do estudante Fernando reflete a importância que esses elementos, que compõem o vestuário e a 
vida dos estudantes, que fazem parte da cultura juvenil, têm para o grupo social ao qual pertence. Para estes jovens, a roupa, os adereços, tudo que ostentam, que tem valor e que é luxo corresponde a valorização do jovem no grupo, a identificação, reconhecimento, pertencimento e trânsito a determinado grupo social. É o que observamos igualmente na fala seguinte: "Ostentação é se vestir, comprar demais e viver sempre em alta, sempre viver, sempre ostentando [...] porque ninguém quer andar feio, quer andar arrumado, quer andar todo bonitinho". (Larissa). É importante destacar que a cultura da ostentação encontra nas mídias sociais um forte recurso divulgador, aglutinador, de construções e reconstruções de representações sociais, mídias sociais essas acessadas constantemente pelos jovens estudantes.

A cultura da ostentação, para os jovens, constitui-se num elemento poderoso de poder, de identificação, inclusão e codificação do status social dos estudantes no interior de determinados grupos sociais. Deste modo, o tênis e o boné de marca, o relógio, as roupas de "grife", o carro de luxo e tantos outros são mais do que simples elementos de consumo na sociedade. São considerados como demarcadores de culturas juvenis, como passaporte de entrada em grupos sociais, instrumentos de integração e reveladores de identidades grupais (PAIS, 2003). Similarmente, a ausência desses elementos que ostentam, em determinados grupos sociais, pode ser fomento para discriminação e marginalização dos jovens estudantes, o que é expresso na fala de Larissa (Grupo focal, 2016): “Aqui no colégio é uma prova viva disso [...], saiu essa moda de calça alta, se for procurar aqui eu acho que $50 \%$ ou mais tem aqui no colégio". Considerando essa fala, "a moda da calça de cintura alta" é um elemento de ostentação e identificador de poder no espaço escolar, perfilando estilos de vida dos jovens através de elementos consumidos. Neste âmbito, a escola necessita interpretar os diferentes modos de vida dos estudantes, como forma de aproximações sem hierarquização e subalternização, reconhecimento e diálogos com as diferentes culturas juvenis no currículo escolar.

Na dinâmica do conhecimento do estudante pela escola, Pais (2003, p.76) acrescenta que "é impossível compreender as culturas juvenis sem entender o significado que, correntemente, os jovens dão às suas ações, às suas atividades quotidianas”, o que reforça a compreensão da impossibilidade de olhar apenas a juventude pelas lentes de uma cultura juvenil unitária (PAIS, 2003). A juventude está para além e devem ser exploradas não apenas as "possíveis ou relativas similaridades entre jovens ou grupos de jovens (em termos de situações, expectativas, aspirações, consumos culturais, por exemplo), mas também e, principalmente, as diferenças sociais que entre eles existem” (PAIS, 2003, p. 29). Tendo 
como referência este cenário, para dar conta da amplitude e complexidade que envolve a concepção de juventude, é necessário que a escola ultrapasse as fronteiras homogeneizantes que envolvem sua compreensão e conceba a juventude segundo seus aportes históricos, sociais, culturais e econômicos. Entretanto, muitas escolas da EJA ainda avistam os jovens a partir de perfis socialmente estabelecidos, o que ainda dificulta o conhecimento desse jovem concreto que se apresenta em sala de aula.

Em se tratando do currículo, as representações sociais, expressas no grupo focal, configuram o currículo como um Documento Normatizador. O currículo está implicitamente atrelado à imagem do documento normatizador do histórico escolar da transferência, envolvendo o percurso escolar dos estudantes: notas (aprovados/reprovados), disciplinas, carga horária, observações e demais informações pertinentes a esse documento, o que é inferido pela fala da estudante: "É, professora, porque tipo, se você é expulso de um colégio, como é que o outro vai saber? Então, quando você pede o documento do colégio para levar para outro, acho que ali vão todas as informações daquele aluno. É por isso que chegar lá ele vai saber se é um bom aluno, se for mau aluno, se ficou, se foi expulso. Com vários colégios acontece isso, não sei se em todos, mas acho que em vários acontece" (Larissa). É importante ressaltar, que no universo da Educação de Jovens e Adultos, documentos de transferências, notas, número de faltas são potencializados por conta dos seus percursos escolares de carências, repetências, desistências e tantos outros elementos envolvendo a vida destes estudantes.

Essa RS dos estudantes em relação ao currículo escolar, como um documento normatizador, nos leva a inferir sobre a ausência de uma cultura de participação dos estudantes na construção do currículo escolar como um artefato socialmente e culturalmente construído, o que provoca silenciamentos historicamente construídos, distanciamentos e negações de reconhecimentos dos diferentes contextos de vida dos estudantes da EJA, pois [...] em estruturas fechadas, nem todo conhecimento tem lugar, nem todos os sujeitos e suas experiências e leituras de mundo têm vez em territórios tão cercados (ARROYO, 2013, p. 17). Nesta significância, contemplar na esfera escolar um currículo socialmente construído, com autoria dos estudantes da EJA, demanda esforços, aproximações, embates e disputas territoriais (ARROYO, 2013). Neste sentido, o envolvimento e a efetiva participação dos estudantes é uma das chaves de entendimento na autoria de um currículo, que deve ser corajosamente revisitado e reconstruído em movimentos constantes, no sentido de retratar e traduzir a composição plural da escola, decodificando as experiências e contextos individuais 
e coletivos dos jovens estudantes da EJA. Essa tradução deve ser resultante dos compartilhamentos através dos diálogos e trocas coletivas, exercitados pela comunidade escolar, principalmente pelos estudantes.

\subsection{Os desafios e possibilidades na construção de um currículo que atenda a cultura juvenil}

Intencionando fomentar uma discussão, no grupo focal, junto aos estudantes, sobre os desafios e possibilidades na construção de um currículo voltado para a cultura juvenil, organizamos alguns questionamentos. São eles: Em relação às atividades propostas aos estudantes, o que vocês acham do trabalho desenvolvido pela escola em relação à cultura juvenil? Quais são os maiores desafios que os jovens encontram no ambiente escolar em relação a sua cultura juvenil? Como você acha que a escola pode trabalhar com sua forma de ver, sentir e estar no mundo? Para aproximar as atividades escolares dos contextos de vida de vocês, que sugestões você daria a escola? A seguir, apresentamos as Representações Sociais dos desafios e das possibilidades sob o olhar dos estudantes.

Como desafio, os estudantes apontam o reconhecimento das diferentes culturas juvenis no currículo escolar. Os diálogos e discussões travados no grupo focal despiram um cenário visceralmente plural, mas ao mesmo tempo invisibilizado no cotidiano escolar, o que é retratado nas falas seguintes, ao discutirem cultura no grupo focal: "Cultura é tudo o que o ser humano faz". (Lucas); "É um conjunto de raças, de cores, acho que é isso". (Gabriel); "Cultura cada um tem a sua cultura, seus pontos de vista, ver como são as coisas, de se expressar". (Camila); e "Porque eu ajo de uma forma e ela de outra, eu tenho uma personalidade e ela outra, somos diferentes em todos os sentidos [...] só pela cor, pelo vestir, de falar, de agir, do jeito de pensar, somos diferentes pela religião, somos totalmente diferentes". (Valentina). Os estudantes traduzem naturalmente os contextos heterogêneos presentes na escola, quando anunciam em suas falas essa diversidade: "somos diferentes em tudo", diferenças demarcadas pela cor, pelo vestir, pelo falar, pela religião, dentre outros, o que confere que o cotidiano não é engendrado em um vazio social (DOS SANTOS COSTA, 2009).

Entretanto, estas heterogeneidades, já discutidas anteriormente, encontram negações no espaço e no currículo escolar, o que é demonstrado claramente na fala do estudante Artur: “O jovem com o boné hoje, por exemplo, com o boné na cara, é discriminado. Pensa que o 
cara não é de boa aparência, que tá usando o boné assim na cara de outro jeito e pensa que aquele jovem não é de boa aparência". (Artur). O "boné” é um dos elementos da cultura juvenil na atualidade, entretanto, a fala do estudante supracitado é um indício da ausência de reconhecimento deste elemento como marcador da cultura juvenil. O estudante ainda anuncia que em muitos contextos sociais o jovem que usa o boné é discriminado, visto que o boné, em alguns contextos da atualidade, é associado a um componente negativo da composição do vestuário dos jovens, o que em muitos casos demanda restrições do seu uso no espaço escolar. Neste contexto, as representações sociais dos estudantes, frente a questionamentos que giram em redor da cultura e do currículo no grupo focal, nos fazem compreender que o grande desafio é o reconhecimento das diferentes culturas juvenis no currículo escolar.

Em conjunto com o boné, o piercing, as tatuagens, os alargadores de orelhas devem ser percebidos como elementos aglutinadores dos jovens e, portanto, fazendo parte de diferentes culturas juvenis. Contudo, em determinados contextos sociais soam como elementos discriminatórios e excludentes. Vejamos: “Tem os piercings também, tem pessoas que gostam de usar, outras pessoas não gostam e aí, muitas vezes, principalmente mulher, tem o rosto cheio de piercings, tem gente que vê como se aquela mulher não prestasse, só que eu acho que é uma cultura, cada um usa porque gosta". (Camila). O fato é que esses elementos, em determinados contextos sociais, ao invés de dar um sentido identitário aos jovens, muitas vezes se constituem em etiquetas para entendimentos marginais e negativos referentes aos jovens, o que é reforçado na fala da estudante: "Sim, eu acho que é uma cultura, é um desejo, mas eu me sinto bem, eu gosto, eu uso. Eu sei que por isso a sociedade me discrimina, me julga. Eu sei, por usar roupa curta, por eu usar piercings, brincos e ter tatuagens. Eu sei que a sociedade me julga, mas eu não me importo com isso, eu sei que vivo do meu jeito [...] então não vou me importar com isso". (Valentina).

As narrativas dos estudantes no contexto da investigação realizada ainda anunciam que a ausência do reconhecimento das diferentes culturas juvenis ocasiona preconceitos, exclusões e, em grande parte, subalternizações culturais, como pode ser percebido nas falas seguintes: "Para mim, o maior desafio para o jovem aqui no colégio é o preconceito. Porque tem muita gente preocupada com o modo como a pessoa se veste, se tem o cabelo black. 'Que cabelo de bicho, que cabelo feio!'. Se a pessoa coloca uma roupa, falam que é roupa escandalosa [...]”. (Sofia); “Tem gente que gosta de cabelo mais, cabelo mais black, tem gente que fica incomodado, cabelo duro. Já vi algumas pessoas agredir, ofender com palavras ‘cabelo feio, por que não dá uma pranchinha, uma escova?’. Eu acho assim, tipo, assim, se ele 
está vivendo bem desse modo que ele escolheu, ela tem mais é que desfrutar disso, porque está a alegrando, se sentindo bem com isso, se não ele vai brincar com seus sentimentos". (Sofia). A riqueza dessas falas desvela outros elementos da cultura juvenil e a forma como assumem seus cabelos e identidades, e, ao mesmo tempo, denunciam os preconceitos e estranhamentos no espaço escolar sobre os cabelos "black", que têm como pano de fundo padrões culturais hegemônicos e hierarquizantes (MUNANGA, 2005). Neste sentido, o currículo, em muitas escolas, ainda se constitui de mensagens subjacentes, de conteúdos que expressam domínio de uma cultura dominante (SILVA, 2007), (MUNANGA, 2005).

Neste cenário, ante o desafio do reconhecimento, quando questionam crenças, posicionamentos, valores e verdades únicas, os estudantes apontam possibilidades nas suas falas, na superação de um currículo homogeneizante, seletivo e excludente para novas incursões curriculares, abrindo espaços para as transgressões, lutas, resistências e visibilizações dos enredamentos das diferentes culturas juvenis. As narrativas dos estudantes são reveladoras dos diferentes cenários das culturas juvenis e da necessidade de reconhecimento dos mesmos no currículo da Educação de Jovens e Adultos, o que demarca a necessidade da escola revisitar corajosamente o seu currículo escolar, uma vez que o currículo também é visto como um campo de transgressões culturais (ARROYO, 2013).

A escola e o currículo são convidados a se reinventar (CANDAU, 2010), firmando espaços de diálogos interculturais, entendidos aqui como uma construção que "se configura como o processo de encontro entre pessoas de diferentes origens étnicas, culturais, religiosas e linguísticas, com a finalidade de intercambiar opiniões desde uma postura horizontal da comunicação" (DOS SANTOS COSTA, 2012, p.156). Nesta conjuntura, o diálogo intercultural é apontado como possibilidade para a construção de um currículo que atenda à cultura juvenil, posto que esse jovem necessariamente precisa ser percebido dentro do espaço escolar, a partir de seus pertencimentos, que estão latentes no espaço escolar, o que pode causar, em alguns casos, desconfortos e embates diante das invisibilidades e negações desta forma juvenil de ser e estar no mundo, deixando transparecer que as questões atuais que envolvem a juventude não estão suficientemente claras para as escolas que ofertam a EJA.

Para tanto, as narrativas dos estudantes apontam diferentes estratégias metodológicas na consolidação desses diálogos interculturais, a exemplo da música, da dança, do canto, do teatro, do encontro para debates, que oferecem diferentes formas de materialização dos diálogos interculturais no currículo escolar. Neste viés, a escola deve conhecer e se aproximar 
das variadas formas de ser jovem, o que pode despertar nela um debate fecundo sobre juventude e sobre currículo no trabalho com a cultura juvenil.

\section{Algumas considerações}

Neste artigo, buscou-se analisar as representações sociais dos estudantes da Educação de Jovens Adultos acerca de currículo e juventude, ressaltando os desafios e possibilidades para a construção de um currículo que atenda a cultura juvenil. É fato que a Educação de Jovens e Adultos no Brasil, historicamente, sempre emanou tensões, complexidades e desafios de múltiplas ordens, no decorrer de contextos políticos, econômicos, sociais e culturais. $\mathrm{Na}$ atualidade, aliada a outras tensões, esta modalidade de ensino enfrenta a complexidade e os desafios trazidos por um processo de Juvenilização, em ascensão desde a década de 1990, processo esse que demarca a presença cada vez mais de estudantes jovens em salas de aula da EJA.

As representações sociais dos estudantes sobre juventudes, descortinadas durante a investigação, em uma escola pública da rede estadual de ensino do Estado da Bahia, traduzem as juventudes: como um recorte etário, como uma cultura de ostentação; como um valor; além de serem apresentadas como sinônimo de rebeldia e violência.

Nesta conjuntura, dialogar e interpretar essas representações sociais das juventudes no âmbito do seu reconhecimento é tratar dos silenciamentos das marcas das diferentes culturas juvenis na escola e, consequentemente, no currículo da Educação de Jovens e Adultos. Além disso, estas representações sociais abrem a inevitabilidade da escola imergir de forma mais aprofundada sobre o cotidiano das juventudes, no conhecimento destas representações sociais refletidas na investigação, no sentido de provocar uma maior aproximação com as pluralidades inerentes aos contextos de vida dos jovens e, principalmente, das pluralidades encontradas em cada estudante presente nas classes da EJA, que espelham distintos posicionamentos, novos comportamentos, novas formas de se vestir, de se comunicar, de linguagens, dentre outros aspectos.

A investigação também anuncia a premência de a escola conhecer e interpretar as representações sociais dos estudantes da EJA, possibilitando diálogos sem apartamentos de ideias, com destino a oportunizar e potencializar a desconstrução e reconstrução de representações sociais e, consequentemente, reconhecendo as diferentes juventudes instaladas nas classes da EJA, que, por muitas vezes, são silenciadas e subalternizadas por culturas 
hegemônicas, hierarquicamente construídas, o que ocasiona elucidações e entendimentos para as diferentes realidades sociais e culturais experienciadas pelos jovens estudantes da EJA.

Em continuidade, a investigação também apresenta que as representações sociais dos estudantes sobre currículo se resguardam em compreender o currículo como um documento normatizador, ou seja, o currículo, para os estudantes da EJA, invoca a ideia de histórico escolar, notas, faltas, disciplinas, transferência, o que colabora para inferirmos sobre as ausências de uma cultura de participação dos estudantes nas configurações curriculares historicamente, socialmente e culturalmente construídas.

Neste cenário, a Juvenilização da EJA reclama por esforços para visibilizar e reconhecer, no âmbito do currículo escolar, as juventudes plurais, alicerçadas aqui pelo viés sociocultural, e suas diferentes culturas juvenis, justificadas pelas práticas cotidianas, modos, estilos de vida, valores, dentre outros aspectos que demarcam as diferentes juventudes.

Este desafio demanda por respostas curriculares e formativas que favoreçam uma maior aproximação das juventudes presentes na EJA. Para tal, é fundamental revistar seus currículos, seus planejamentos, suas estratégias metodológicas, o que sublinha para a urgência de práticas formativas horizontais e insurgentes: investir nos percursos formativos dos gestores, coordenadores e professores; apropriar-se e reconhecer as diferentes culturas juvenis; desconstruir modelos de currículos hermeticamente fechados e inflexíveis, potencializando novos giros curriculares, pautando-se em epistemologias dialógicas.

Nestas novas configurações curriculares, a escola é convocada a forjar o seu cotidiano, tendo em vista as especificidades da EJA, o que indica a necessidade de romper com modelos de escolas fechadas e fronteiriças a contextos culturais diversos, com currículos e práticas pedagógicas pasteurizadas e solidificadas em vazios culturais. Estes rompimentos demandam movimentos de novas arquiteturas na Educação de Jovens e Adultos, a partir do conhecimento dos contextos das juventudes e da apreensão, interpretação e reconhecimento de suas culturas juvenis, intencionando configurar elementos nas reconfigurações da EJA.

Construir movimentos opositores a currículos homogeneizantes é favorecer que sejam revelados os sentidos e significados dos diferentes modos de ser das diferentes formas de se comportar e conviver no mundo, e tantas outras demarcações impressas na vida dos jovens. Para esse fim, a escola e o currículo necessitam conceber e exercitar, com horizontalidade, movimentos dinâmicos, porém complexos, de aproximações com a comunidade escolar, com as juventudes, intencionando interagir, dialogar, desvelar, interpretar e reconhecer as heterogeneidades em sala de aula. 
As heterogeneidades, constitutivas da cultura juvenil, são entalhadas pelas representações sociais construídas em diferentes locais de convívio e contextos de vida dos jovens estudantes da EJA, a exemplo das interações no bairro em que moram, na igreja, na família, na escola, na praça, nas redes sociais, nos programas de TV, no rádio, dentre outros, sendo a escola, sinalizada por esta investigação como um local propício para a construção e reconstrução das representações sociais, dado que, ao adentrarem a escola, os estudantes interagem de diferentes formas, lançam olhares inquiridores sobre diferentes contextos, dialogam e trocam ideias, se aproximam e conhecem o "outro", constituindo-se a escola como um espaço de concordâncias e discordâncias, como uma arena de discussões e intercâmbios para a construção e reconstruções de representações sociais gestadas a partir de diferentes práticas sociais. Portanto, a escola é um local privilegiado para as interações da comunidade escolar, melhor dizendo, um local propício para promover aproximações e reconhecimentos das diferentes culturas juvenis.

Quanto aos desafios e possibilidades para a construção de um currículo que atenda as culturas juvenis, as narrativas dos estudantes anunciam como desafio a necessidade e urgência no reconhecimento das diferentes culturas juvenis presentes no espaço escolar e no currículo, bem como a superação de preconceitos, hierarquizações e subalternizações culturais de diferentes saberes. Sublinham o diálogo intercultural como possibilidade para a construção de um currículo que atenda a cultura juvenil, respeitando as autorias outras formas de saberes e fazeres curriculares. Neste intuito, os estudantes ressaltam na investigação a possibilidade da escola potencializar a dança, a musica, o teatro, como formas de diálogos e aproximações da escola, do currículo com as diferentes juventudes presentes nas classes de Educação de Jovens e Adultos.

\section{REFERÊNCIAS}

ABRAMOVAY, Miriam et alii. Juventude, violência e vulnerabilidade social na América Latina: desafios para políticas públicas. Brasília : UNESCO, BID, 2002. Disponível; http://unesdoc.unesco.org/images/0012/001271/127138por.pdf Acesso: 17/04/2020.

APPLE, Michael W. Repensando ideologia e currículo. In: MOREIRA, Antônio Flávio, SILVA, Tomaz Tadeu da Silva (org). Currículo, cultura e sociedade; tradução de Maria Aparecida Baptista - 10.ed - São Paulo: Cortez, 2008, p. 49-69. 
ARROYO, Miguel González. Outros Sujeitos, Outras Pedagogias. Petrópolis, RJ: Vozes, 2014.

ARROYO, Miguel González. Currículo, território em disputa. - Petrópolis, RJ: Vozes, 2013.

ARROYO, Miguel González. Educação de jovens e adultos: um campo de direitos e de responsabilidade pública. In: SOARES, Leôncio, GIOVANETTI, Maria Amélia, GOMES, LINO, Nilma . Diálogos na Educação de Jovens e Adultos. Belo Horizonte: Autêntica Editora, 2011.

BARDIN, Laurence. Análise de Conteúdo; tradução, Luis Antero Reto e Augusto Pinheiro. Lisboa: Edições 70, 1977.

BRASIL, Ministério da Educação. LEI de n ${ }^{\circ}$ 9394/96, de 20/12/1996. Lei de Diretrizes e Bases da Educação Nacional. Disponível:

http://www.planalto.gov.br/ccivil_03/Leis/L9394.htm Acesso: 10/05/2020.

BRASIL. Constituição da Republica Federativa do Brasil. Brasília: Senado Federal, 1988. Disponível: http://www.planalto.gov.br/ccivil_03/constituicao/ConstituicaoCompilado.htm Acesso: 10/05/2020.

BRANCO, Pedro Paulo Martoni. Juventude e trabalho: desafios e perspectivas para as politicas públicas. In: ABRAMO, Helena Wendel, BRANCO, Pedro Paulo Martoni. Retratos da Juventude Brasileira. Análise de uma Pesquisa Nacional. São Paulo: Edição Fundação Perseu Abramo e Instituto da Cidadania, 2011.

BRUNEL, Carmem. Jovens cada vez mais jovens na educação de jovens e adultos. Porto Alegre: Mediação, 2014.

CANDAU, Vera Maria. Construir Ecossistemas Educativos - Reinventar a Escola. In: CANDAU, Vera Maria (org). Reinventar a Escola. Petrópolis, RJ: Vozes, 2010.

CASTRO, P. A de. Tornar-se aluno: identidade e pertencimento - um estudo etnográfico. 2011. 157f. Tese (Doutorado em Educação) - Faculdade de Educação, Universidade do Estado do Rio de Janeiro, Rio de Janeiro, 2011, p. 158.

DAYRELL, Juarez. A juventude e a educação de jovens e adultos: reflexões iniciais - novos sujeitos. In: SOARES, Leôncio, GIONANETTI, Maria Amélia e GOMES, Nilma Lino. Diálogos na Educação de Jovens e Adultos. Belo Horizonte: Autêntica, 2011, p. 53-67.

DEBERT, Guita. A dissolução da vida adulta e a juventude como valor. 2010. Disponível: http://www.scielo.br/scielo.php?script=sci_arttext\&pid=S0104-71832010000200003 Acesso: $12 / 05 / 2020$.

DI PIERRO, Maria Clara, JOIA, Orlando e RIBEIRO, Vera Masagão. Visões da Educação de Jovens e Adultos no Brasil. Cadernos Cedes, ano XXI, nº 55, novembro/2001. Disponível em: http://www.scielo.br/pdf/ccedes/v21n55/5541.pdf Acesso: 12/05/2020. 
DOS SANTOS COSTA. Graça. Didática e formação Continuada para a Diversidade Cultural: perspectivas e desafios. In: SUANNO, Marilza e RAJADELL, Núria (orgs). Didática e Formação de Professores; Perspectivas e Inovações. Goiânia: CEPED Publicações e PUC Goiás, 2012, 133-161.

DOS SANTOS COSTA. Graça. Diálogo entre família e escola em contexto de diversidade: uma ponte entre expectativas e realidades. Tese doutoral. Departamento de Didática e Organização Educativa. Barcelona: Universidade de Barcelona, 2009. Disponível em: http://tdx.cat/handle/10803/1374. Acesso: 13/05/2020.

FRAGA, Paulo Cesar Pontes e LULIANELLI, Jorge Atílio Silva (orgs). Jovens em Tempo Real. Rio de Janeiro: DP\&A, 2003.

GATTI, Bernadete Angelina. Grupo focal na pesquisa em Ciências Sociais e Humanas. Brasília: Líber Livro Editora, 2005.

GIDDENS, Anthony. Modernidade e Identidade. Rio de Janeiro: Jorge Zahar Editor, 2002.

GIL, Antônio Carlos. Métodos e técnicas de pesquisa social. 5. ed. São Paulo: Atlas, 2009.

GROPPO, Luiz Antônio. Juventude. Ensaios sobre Sociologia e História das Juventudes Modernas. Rio de Janeiro: DIFEL, 2000.

GUARESCHI, Pedrinho, JOVCHELOVITCH, Sandra (orgs.). Textos em Representações Sociais. 8.ed. Petrópolis, RJ: Vozes, 1995.

JODELET, Denise. Loucuras e representações sociais. Petrópolis: Editora Vozes, 2001.

LUDKE, Menga e ANDRE, M.E.D.A. Pesquisa em Educação: abordagens qualitativas. São Paulo: EPU, 1986.

MAIA, Carla Valéria Vieira Linhares. Cartografias Juvenis: mudanças e Permanências nos Territórios de Ser Jovem. 2010. 361f. Tese (Doutorado em Educação). Faculdade de Educação da Universidade Federal de Minas Gerais, Minas Gerais. 2010. Disponível em: https://repositorio.ufmg.br/bitstream/1843/BUOS-

8FNQE4/1/cartografias_juvenis_mudan_as_e_perman_ncias_nos_territ_rio.pdf Acesso: 12/05/2020.

MELLOWS, David, DOS SANTOS COSTA, Graça.; COSTA, Patrícia Lessa. Educação de jovens e adultos, Currículo e formação. Apresentação do dossiê da Revista Internacional de Educação de Jovens e Adultos - RIEJA. no prelo. 2020.

MINAYO, Maria Cecília de Souza. Ciência, técnica e arte: O desafio da pesquisa sócial. In MINAYO, Maria Cecília de Souza. (orgs.) Pesquisa social: teoria, método e criatividade/ Suely Ferreira Deslandes, Otávio Cruz Neto, Romeu Gomes. - Petrópolis, RJ: Vozes, 2013, p. 9-29.

MOREIRA, Antônio Flávio e CANDAU, Vera Maria (orgs). Multiculturalismo. Diferenças Culturais e Práticas Pedagógicas. Petrópolis, RJ: Vozes, 2013. 
MOREIRA, Antônio Flávio e SILVA, Tomaz Tadeu (orgs). Currículo, cultura e sociedade;-12.ed - São Paulo: Cortez, 2011.

MOSCOVICI, Serge. Representações Sociais. Investigações em psicologia social. Petrópolis, RJ: Vozes, 2012.

MORENO, Gilberto Geribola. Jovens e Experiência Social na Educação de Jovens e Adultos. 2010. Dissertação (Mestrado em Educação) - Faculdade de Educação, Universidade de São Paulo, São Paulo, 2010. Disponível em:

https://teses.usp.br/index.php?option=com_jumi\&fileid=17\&Itemid=160\&id=77A14D3EE2D 7\&lang=pt-br Acesso: 12/05/2020.

MUNANGA, Kabengele. (org). Superando o Racismo na Escola. - 2.ed. - Brasília: Ministério da Educação, Secretaria de Educação Continuada, Alfabetização e Diversidade, 2005. Disponível: http://portal.mec.gov.br/secad/arquivos/pdf/racismo_escola.pdf Acesso: 02/05/2020.

OLIVEIRA, Maria Da Conceição Cédro Vilas Bôas de. Currículo e culturas juvenis: um estudo de caso sobre as representações sociais dos estudantes da Educação de Jovens e Adultos no município de Conceição da Feira-BA. 2016. 245 f. Dissertação (Mestrado) Programa de Pós-Graduação Profissional em Educação de Jovens e Adultos, Universidade do Estado da Bahia, Salvador, 2016.

ONU, Organizações das Nações Unidas. Declaração Universal dos Direitos

Humanos,1948. Disponível: http://www.onu.org.br/img/2014/09/DUDH.pdf. Acesso: 10/04/2020.

PAIVA, Vanilda Pereira. Educação popular e educação de adultos. São Paulo: Edições Loyola, 1987.

PAIS, José Machado. Culturas juvenis. Lisboa: Imprensa Nacional-Casa da Moeda, 2003.

PEDRA, José Alberto. Currículo, Conhecimento e suas Representações. Campinas, SP: Papirus, 1997.

PEREIRA, T. V.; OLIVEIRA, R. A. A. Juvenilização da EJA como efeito colateral das políticas de responsabilização. Estudos em Avaliação Educacional, São Paulo, v. 29, n. 71, p. 528-553, maio/ago. 2018.

PINHO, Clarice Wilken de. Educação e Cultura Popular nas Propostas Escolares da EJA - Educação de Jovens e Adultos: um estudo em duas escolas de Belo Horizonte. 2016. Dissertação (Mestrado em Educação) - Universidade Federal de Minas Gerais, Minas Gerais. 2016. Disponível em: https://repositorio.ufmg.br/handle/1843/BUBD-ACEFNY Acesso: $12 / 05 / 2020$.

RIBEIRO, Renato Janine. Política e Juventude: o que fica da energia. In: NOVAES, Regina, VANNUCHI, Paulo. Juventude e Sociedade. Trabalho, Educação, Cultura e Participação. São Paulo: Edição Fundação Perseu Abramo e Instituto da Cidadania, 2004, p. 19-33. 
SACRISTÁN, J. Gimeno.. O currículo: uma reflexão sobre a prática; tradução Ernani F. da F. Rosa. - $3^{\circ}$. ed. - Porto Alegre: Artmed, 2000.

SILVA, Tomas Tadeu da. Documentos de identidade: uma introdução às teorias do currículo. $2^{\mathrm{a} e d ., ~} 11^{\mathrm{a}}$ reimp. - Belo Horizonte: Autêntica, 2007.

SILVA, A. de J. da et al. Educadores de jovens trabalhadores que estudam: aprendendo a ensinar. In: Diálogos com a juventude presentes na EJA. Analice da Silva (Org.) Belo Horizonte: Mazza Edições, 2014.

SPOSITO, Marília Pontes. (coord.). O Estado da arte sobre juventude na pós-graduação brasileira: Educação, Ciências Sociais e Serviço Social (1999-2006). Belo Horizonte: Argumentum Editora, 2009. Volume 1.

VALE, Zoé Margarida Chaves Vale. Encontros e desencontros entre jovens e a escola: sentidos da experiência escolar na educação de jovens e adultos - EJA. 2007. Dissertação (Mestrado em Educação) - Universidade Federal de minas Gerais, Belo Horizonte-MG. 2007. Disponível em: http://www.bibliotecadigital.ufmg.br/dspace/bitstream/1843/VCSA7WNEVA/1/encontros_e_desencontros_entre_os_jovens_e_a_escola.pdf Acesso: $\underline{12 / 05 / 2020 .}$

WAISELFISZ, J. J. (2015). O mapa da violência 2015: Mortes Matadas por Armas de Fogo Disponível: http://www.mapadaviolencia.org.br/pdf2015/mapaViolencia2015.pdf

\section{SOBRE AS AUTORAS:}

\section{Maria da Conceição Cédro Vilas Bôas de Oliveira}

Mestre em Educação de Jovens e Adultos pela Universidade do Estado da Bahia. Centro Estadual de Educação Profissional Áureo de Oliveira Filho/ Feira de Santana/ Bahia/Brasil. Membro grupo de educação, direitos humanos e Interculturalidade (GREDHI). E-mail: mariaoliveira1704@gmail.com.

\section{iD http://orcid.org/0000-0001-9516-4590}

\section{Graça dos Santos Costa}

Doutora em Pedagogia pela Universidade de Barcelona (UB). Professora titular da Universidade do Estado da Bahia (UNEB) e professora associada da Universidade de Barcelona (UB). Líder do grupo de educação, direitos humanos e Interculturalidade (GREDHI) e membro do grupo de Grupo de pesquisa e Assessoramento didático(GIAD). Email: gracacosta@gmail.com

(iD http://orcid.org/0000-0001-7770-0118 